\title{
The Study of Structure and Properties \\ of Nanoporous Carbon Materials Obtained by Alkaline Thermal Activation of Lignin of Fir Wood
}

\author{
Ivan P. Ivanov*, \\ Nadezhda M. Mikova, Maxim A. Lutoshkin, \\ Nikolay V. Chesnokov and Boris N. Kuznetsov \\ Institute of Chemistry and Chemical Technology SB RAS \\ FRC "Krasnoyarsk Science Center SB RAS" \\ 50/24 Akademgorodok, Krasnoyarsk, 660036, Russia
}

Received 13.01.2017, received in revised form 27.03.2017, accepted 18.07.2017

\begin{abstract}
Synthesis of nanoporous carbon materials (NCMs) from lignin of fir wood in the presence of potassium hydroxide was carried out by varying the carbonization conditions at $800^{\circ} \mathrm{C}$. Using the methods of nitrogen adsorption at $77 \mathrm{~K}$ and scanning electron microscopy, the influence of conditions of lignin carbonization on the formation of a porous structure of the NCMs was studied. The obtained samples of NCMs, have specific surface area up to $3157 \mathrm{~m}^{2} / g$, pore volume up to $1.92 \mathrm{~cm}^{3} / \mathrm{g}$, fraction of micropores up to $92.2 \mathrm{rel}$. \%, average pore size of $1.88-2.43 \mathrm{~nm}$ and have a high sorption capacity for benzene (up to $1.41 \mathrm{~g} / \mathrm{g}$ ).
\end{abstract}

Keywords: ethanol lignin, alkaline lignin, alkaline thermal activation, nanoporous carbon material, properties.

(C) Siberian Federal University. All rights reserved

* Corresponding author E-mail address: ivanov@icct.ru 


\title{
Изучение строения и свойств нанопористых \\ углеродных материалов, полученных \\ термощелочной активацией \\ лигнинов древесины пихты
}

\author{
И.П. Иванов, Н.М. Микова, \\ М.А. Лутошкин, Н.В. Чесноков, Б.Н. Кузнецов \\ Институт химии и химической технологии СО РАН \\ ФИЦ «Красноярский научный иентр СО РАН» \\ Россия, 660036, Красноярск, Академгородок, 50/24
}

Осуществлен синтез нанопористых углеродных материалов (НУМ) из лигнинов пихты путем вариации условий процесса карбонизации в присутствии гидроксида калия при $800{ }^{\circ} \mathrm{C}$. С использованием методов адсорбиии азота при $77 \mathrm{~K}$ и сканирующей электронной микроскопии изучено влияние условий карбонизации лигнинов на формирование пористой структуры НУМ. Полученные образиьь НУМ имеют удельную поверхность до $3157 \mathrm{~m}^{2} / 2$, объем пор до 1,92 см²/2, долю микропор до 92,2 отн. \%, средний размер пор 1,88-2,43 нми и обладают высокой сорбиионной емкостью по бензолу (до 1,41 г/2).

Ключевые слова: этаноллигнин, щеелочной лигнин, щелочная термоактиващия, нанопористый углеродный материал, свойства.

\section{Введение}

Производство пористых углеродных материалов является одним из крупнотоннажных направлений утилизации отходов лесозаготовки и переработки древесины. В настоящее время возрастает интерес к получению нанопористых углеродных адсорбентов, способных проявлять молекулярно-ситовые свойства [1-4].

Для получения нанопористых углеродных материалов (НУМ) наиболее эффективны методы химической активации исходного сырья, основанные на введении в сырье химических добавок с последующей карбонизацией в инертной среде. В качестве химических промоторов используют такие соединения, как $\mathrm{H}_{3} \mathrm{PO}_{4}$, карбонаты или оксиды щелочных металлов и др. [5-8]. При повышенной температуре в процессе карбонизации промоторы способствуют удалению кислорода и других гетероатомов из сырья и развитию пористой структуры углеродного материала.

На формирование пористой структуры углеродного материала в процессе химической активации-карбонизации влияют такие основные факторы, как природа и количество химического реагента, интенсивность нагрева, конечная температура активации, продолжительность процесса и др. В литературе имеются лишь ограниченные сведения о влиянии указанных факторов на выход и строение НУМ, получаемых химической активацией древесного сырья и его основных компонентов, в частности лигнина [9-11].

$$
-391-
$$


Целью настоящей работы являлось изучение строения и свойств нанопористых углеродных материалов, полученных при вариации условий карбонизации в присутствии гидроксида калия из лигнинов, выделенных из древесины пихты различными методами.

\section{Экспериментальная часть}

Для получения этаноллигнина 100 г высушенной древесины пихты помещают в реактор автоклавного типа объемом 2 л и добавляют 1000 мл водно-спиртового раствора с концентрацией этанола в растворе 60 \% масс. Автоклав герметизируют, трижды продувают током аргона для удаления воздуха. Затем производят нагрев до $200{ }^{\circ} \mathrm{C}$ со скоростью $8{ }^{\circ} \mathrm{C} /$ мин и выдерживают при заданной температуре 180 мин.

После охлаждения до комнатной температуры содержимое автоклава фильтруют на воронке Бюхнера и промывают твердый остаток 60 \%-м водно-этанольным раствором той же концентрации, что и реакционный раствор. Профильтрованный щелок и промывные воды объединяют, охлаждают до $4{ }^{\circ} \mathrm{C}$ и добавляют охлажденную до $4{ }^{\circ} \mathrm{C}$ дистиллированную воду из соотношения 3 весовые части $\mathrm{H}_{2} \mathrm{O}$ на 1 весовую часть щелока. Для осаждения лигнина щелок выдерживают при комнатной температуре 12 ч. Затем укрупненный этаноллигнин (ЭЛ) фильтруют и сушат при $50{ }^{\circ} \mathrm{C}$ в сушильном шкафу до постоянной массы.

Выделение щелочного лигнина (ЩЛ) из древесины пихты проводят после предварительного гидролиза гемицеллюлоз 2 \%-ным раствором $\mathrm{HCl}$ в течение 3 ч. По окончании гидролиза опилки отфильтровывают, а остаток на фильтре промывают горячей водой до нейтральной среды. Затем их переносят в колбу вместимостью 500 мл, добавляют 200 мл 1,0 M NaOH и кипятят в течение 8 ч при температуре $98{ }^{\circ} \mathrm{C}$. После кипячения смесь охлаждают и отфильтровывают с промывкой остатка водой до нейтральной среды. Фильтрат и промывные воды подкисляют до $\mathrm{pH}=5-6$. В результате подкисления лигнин выпадает в осадок. После полного осаждения лигнин фильтруют и высушивают до постоянного веса.

Получение образцов нанопористых углеродных материалов из лигнинов пихты проводят путем карбонизации лигнинов фракции 0-1,0 мм с влажностью 10-12 масс. \% в смеси с твердым гидроксидом калия (КОН) фракции 0-3 мм. Карбонизацию реакционной смеси при соотношении лигнин : щелочь 1:3 проводят в цилиндрическом реакторе объемом 0,5 л в атмосфере аргона при $800{ }^{\circ} \mathrm{C}$ при интенсивности нагрева от 15 до $40{ }^{\circ} \mathrm{C} /$ мин с последующей изотермической выдержкой в течение 1 ч.

После охлаждения до комнатной температуры полученные образцы обрабатывают 1М раствором $\mathrm{HCl}$, промывают горячей водой $\left(\sim 50^{\circ} \mathrm{C}\right)$ до нейтральной реакции среды и отрицательной реакции на $\mathrm{Cl}-$-ионы промывных вод. Полученный образец высушивают в сушильном шкафу при температуре $105-110{ }^{\circ} \mathrm{C}$ до постоянного веса.

Характеристики удельной поверхности и пористой структуры нанопористых углеродных материалов определены из изотерм низкотемпературной адсорбции азота (чистотой 99,999 \%) при температуре 77,4 К, измеренных на объемной вакуумной статической установке ASAP 2029MP-C, Micromeritics. Диапазон равновесных относительных давлений составлял от $10^{-7}$ до 0,994 Р/Ро. Перед проведением анализа образы вакуумировали при $300{ }^{\circ} \mathrm{C}$ в течение 12 ч.

Величину удельной поверхности исследуемых образцов рассчитывали с использованием программного обеспечения ASAP 2020 Micromeritics [12]. Расчет площади удельной поверх- 
ности $\left(\mathrm{S}_{\mathrm{BET}}\right.$, микро- и мезопор) нанопористых углеродных материалов из лигнина древесины пихты определяли с корректировкой интервала $\mathrm{P} / \mathrm{P}_{\mathrm{o}}$ в соответствии с методом, учитывающим наличие микропор [13-15].

Анализ пористости (определение объема пор, микро- и мезопор) нанопористых углеродных материалов выполняли с помощью сравнительного t-метода с использованием уравнения Hurkins-Jura для расчета толщины статистического слоя адсорбата $[16,17]$. Дополнительно было рассчитано распределение микро- и мезопор по размеру с помощью метода теории функционала плотности NLDFT (density functional theory) [18, 19].

Структурно-морфологические исследования поверхности образцов НУМ из щелочного и этанольного лигнина древесины пихты проводили на приборе ТМ-3000 Hitachi.

Статическую сорбцию паров бензола проводили при температуре $25^{\circ} \mathrm{C}$ в эксикаторе с выдержкой в течение 24 ч. Для этого высушенные до постоянного веса при температуре $105{ }^{\circ} \mathrm{C}$ образцы НУМ весом около 1 г взвешивали на аналитических весах Vibra HТ с точностью $\pm 0,0001$ г. После этого образцы помещали в закрытый эксикатор и выдерживали требуемое время. После истечения определенного времени сорбции производили взвешивание образцов ПУМ. По разнице определяли количество сорбированного бензола и пересчитывали на удельную сорбцию сорбируемую 1 г образца.

Элементный состав этаноллигнина определяли с использованием анализатора HCNS-O EA FLASH TM 1112 фирмы «Thermo Quest».

\section{Результаты и обсуждение}

Элементный состав лигнинов, полученный с помощью анализатора HCNS-O EA FLASH, приведен в табл. 1. Выход этаноллигнина и щелочного лигнина соответственно составил 56 и 44 мас. \% от исходного содержания лигнина в древесине пихты. При этом этаноллигнин пихты содержит больше углерода, водорода и меньше кислорода, чем щелочной лигнин.

В результате проведения исследований была изучена пористая структура и сорбционные свойства нанопористых углеродных материалов, полученных при вариации условий карбонизации в плаве гидроксида калия лигнинов, выделенных методами щелочной и органосольвентной экстракции из древесины пихты.

Из приведенных на рис. 1 и 2 изотерм адсорбции азота при 77,4 К на образцах НУМ, из щелочного (рис. 1) и этанольного (рис. 2) лигнина видно, что они имеют резкий подъем в области

Таблица. 1. Элементный состав и зольность лигнинов, выделенных из древесины пихты различными методами

Table 1. Elemental composition and ash content of lignins isolated from of fir wood by different methods

\begin{tabular}{|c|c|c|c|c|c|c|c|}
\hline \multirow{2}{*}{ Образец } & \multicolumn{3}{|c|}{$\begin{array}{c}\text { Содержание } \\
\text { элементов, мас. \% }\end{array}$} & \multicolumn{2}{c|}{$\begin{array}{c}\text { Атомное } \\
\text { соотношение }\end{array}$} & \multirow{2}{*}{$\begin{array}{c}\text { Зольность, } \\
\text { мас. \% }\end{array}$} & $\begin{array}{c}\text { Выход, } \\
\text { отн. \%* }\end{array}$ \\
\cline { 1 - 6 } & $\mathrm{C}$ & $\mathrm{H}$ & $\mathrm{O}$ & $\mathrm{H} / \mathrm{C}$ & $\mathrm{O} / \mathrm{C}$ & & 44 \\
\hline Щелочной лигнин & 64,3 & 5,4 & 30,3 & 1,01 & 0,35 & 0,63 & 56 \\
\hline Этаноллигнин & 67,9 & 6,0 & 26,1 & 1,06 & 0,29 & 0,56 & 56 \\
\hline
\end{tabular}

*от исходного содержания лигнина. 
низких относительных давлений (до 0,1 Р/Ро). Это свидетельствует о развитой микропористости и позволяет отнести их к изотермам 1-го типа. Все полученные изотермы сорбции-десорбции азота на НУМ показывают гистерезис типа Н4 по классификации IUPAC [20], который связывают с присутствием узких щелевидных пор. Основные текстурные характеристики исследуемых образцов представлены в табл. 2.

Известно, что помимо природы активирующего агента температура активации является одним из важных факторов, влияющих на развитие текстурных свойств активированного угля [21]. Вид изотерм для образцов НУМ, полученных из щелочного лигнина при вариации скорости нагрева 5,20 и $40{ }^{\circ} \mathrm{C} /$ мин до $800{ }^{\circ} \mathrm{C}$, показывает, что они имеют практически однотипный характер. Это свидетельствует о слабом влиянии скорости нагрева в процессе карбонизации на развитие пористой структуры получаемых НУМ. Полученные образцы имеют близкие значения удельной поверхности и пористого объема, рассчитанных методом БЭТ (табл. 2). В случае НУМ, полученных из этаноллигнина, происходит увеличение удельной поверхности от 2191 до 3157 м²/Г, а объема пор от 1,04 до 1,92 см³/Г при повышении скорости нагрева от 1 до $40{ }^{\circ} \mathrm{C} /$ мин.

Приведенные на рис. 3 зависимости показывают, что удельная поверхность НУМ из этаноллигнина возрастает при повышении скорости нагрева от 1 до $40{ }^{\circ} \mathrm{C} /$ мин. При этом наиболее резкий рост поверхности наблюдается в интервале скорости нагрева от 1 до $5{ }^{\circ} \mathrm{C} /$ мин. В случае НУМ из щелочного лигнина величина удельной поверхности слабо зависит от скорости нагрева.

Данные, рассчитанные с использованием t-Plot-метода, показывают, что удельная поверхность мезопор достигает для НУМ из щелочного лигнина 237-385 м²/г, а из этаноллигнина $73-624 \mathrm{~m}^{2} / \Gamma$.

Таблица 2. Характеристики нанопористых углеродных материалов, полученных из лигнинов пихты при вариации условий карбонизации при $800{ }^{\circ} \mathrm{C}$ в присутствии КОН

Table 2. Characteristics of nanoporous carbon materials obtained from lignins of the fir wood at a variation of conditions of carbonization at $800{ }^{\circ} \mathrm{C}$ in the presence of $\mathrm{KOH}$

\begin{tabular}{|c|c|c|c|c|c|c|c|c|}
\hline \multirow{2}{*}{$\begin{array}{l}\text { №, } \\
\text { П/П }\end{array}$} & \multirow[t]{2}{*}{ Образец* } & \multicolumn{2}{|c|}{$\begin{array}{c}\text { Удельная } \\
\text { поверхность, } \text { м }^{2} / \Gamma\end{array}$} & \multicolumn{2}{|c|}{ Объем пор, см³/г } & \multirow{2}{*}{$\begin{array}{c}\text { Доля } \\
\text { микропор, } \\
\text { \% отн. }\end{array}$} & \multirow{2}{*}{$\begin{array}{c}\text { Средняя } \\
\text { ширина пор, } \\
\text { нм }\end{array}$} & \multirow{2}{*}{$\begin{array}{c}\text { Сорбция } \\
\text { бензола, } \\
\Gamma / \Gamma\left(г / \mathrm{cm}^{3}\right)\end{array}$} \\
\hline & & $\mathrm{S}_{\mathrm{BET}}$ & $\mathrm{S}_{\text {микро }}$ & общий & микро & & & \\
\hline 1 & ЭЛ-1 & 2191 & 2118 & 1,04 & 0,96 & 92 & 1,88 & 0,70 \\
\hline 2 & ЭЛ-5 & 2679 & 2549 & 1,29 & 1,16 & 90 & 1,89 & 1,01 \\
\hline 3 & ЭЛ-10 & 2798 & 2680 & 1,31 & 1,21 & 92 & 1,92 & 1,05 \\
\hline 4 & ЭЛ-20 & 2921 & 2466 & 1,65 & 1,25 & 76 & 2,25 & 1,17 \\
\hline 5 & ЭЛ-40 & 3157 & 2533 & 1,92 & 1,37 & 67 & 2,43 & 1,41 \\
\hline 6 & ЩЛ-5 & 2219 & 1983 & 1,16 & 0,94 & 81 & 2,10 & 0,88 \\
\hline 7 & ЩЛ-20 & 2233 & 1947 & 1,25 & 0,97 & 78 & 2,24 & 0,96 \\
\hline 8 & ЩЛ-40 & 2078 & 1693 & 1,19 & 0,85 & 71 & 2,30 & 1,00 \\
\hline \multicolumn{8}{|c|}{ Зарубежные промышленные углеродные сорбенты } & 0,35 \\
\hline \multicolumn{8}{|c|}{ Отечественные промышленные углеродные сорбенты } & 0,24 \\
\hline
\end{tabular}

* ЭЛ - этаноллигнин; ЩЛ - щелочной лигнин, цифрами обозначены скорости нагрева $\left({ }^{\circ} \mathrm{C} / \mathrm{мин}\right)$. 
Из изотерм адсорбции азота следует, что формирование пористой структуры НУМ при карбонизации лигнинов пихты в присутствии КОН происходит преимущественно за счет образования микропор. Для НУМ, полученных из щелочного лигнина, объем микропор достигает 0,85-0,97 см $3 /$, что составляет 71-81 отн. \% от суммарного объема пор. Для НУМ из этаноллигнина объем микропор достигает $0,96-1,37 \mathrm{~cm}^{3} / \Gamma$, что соответствует $67-92$ отн. \% суммарного объема пор. При этом средняя ширина пор полученных НУМ находится в узком интервале и составляет для образцов из щелочного лигнина 2,10-2,30 нм, а для образцов НУМ из этаноллигнина - 1,88-2,43 нм, что позволяет отнести полученные НУМ к материалам с высокоразвитой нанопористой структурой.

Полученные зависимости распределения микропор по размерам, рассчитанным по методу NLDFT для образцов НУМ из щелочного (рис. 4) и этанольного (рис. 5) лигнина пихты имеют

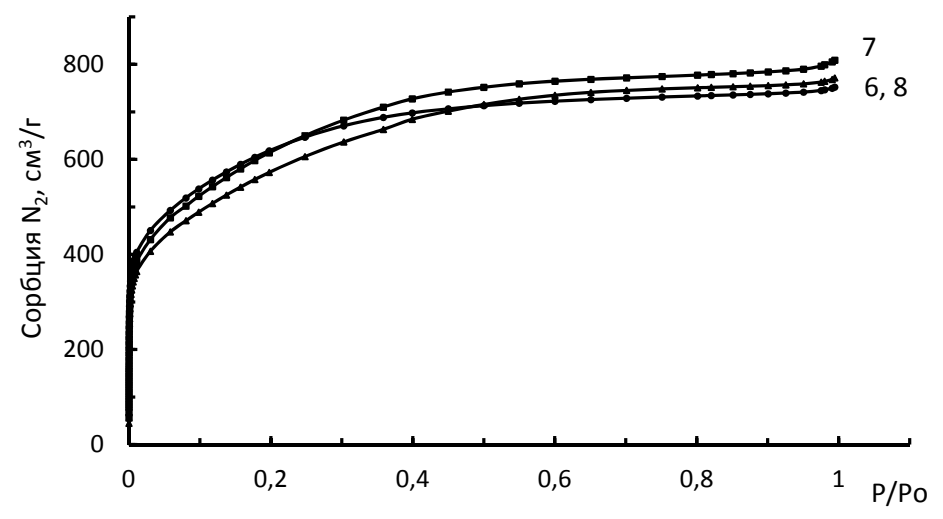

Рис. 1. Изотермы адсорбции азота при $77 \mathrm{~K}$ для образцов НУМ № 6,7 и 8, полученных из щелочного лигнина пихты при скорости нагрева 5,20 и $40{ }^{\circ} \mathrm{C} /$ мин до $800{ }^{\circ} \mathrm{C}$

Fig. 1. Adsorption isotherms of nitrogen at $77 \mathrm{~K}$ for the samples of NCMs № 6, 7 and 8, obtained from alkaline lignin of fir wood at the heating rate 5,20 and $40{ }^{\circ} \mathrm{C} / \mathrm{min}$ to $800^{\circ} \mathrm{C}$

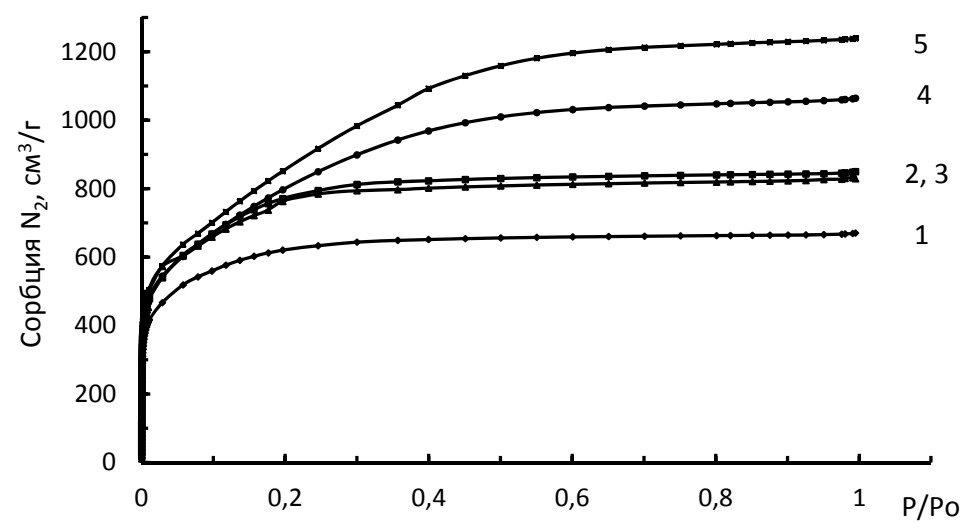

Рис. 2. Изотермы адсорбции азота при 77 К для образцов НУМ № 1, 2, 3, 4 и 5, полученных из этаноллигнина пихты при скорости нагрева $1,5,10,20$ и $40{ }^{\circ} \mathrm{C} /$ мин до $800{ }^{\circ} \mathrm{C}$

Fig. 2. Adsorption isotherms of nitrogen at $77 \mathrm{~K}$ for the samples of NCMs № 1, 2, 3, 4 and 5 obtained from ethanol lignin of fir wood with the heating rate of $1,5,10,20$ and $40{ }^{\circ} \mathrm{C} / \mathrm{min}$ to $800{ }^{\circ} \mathrm{C}$

$$
-395-
$$




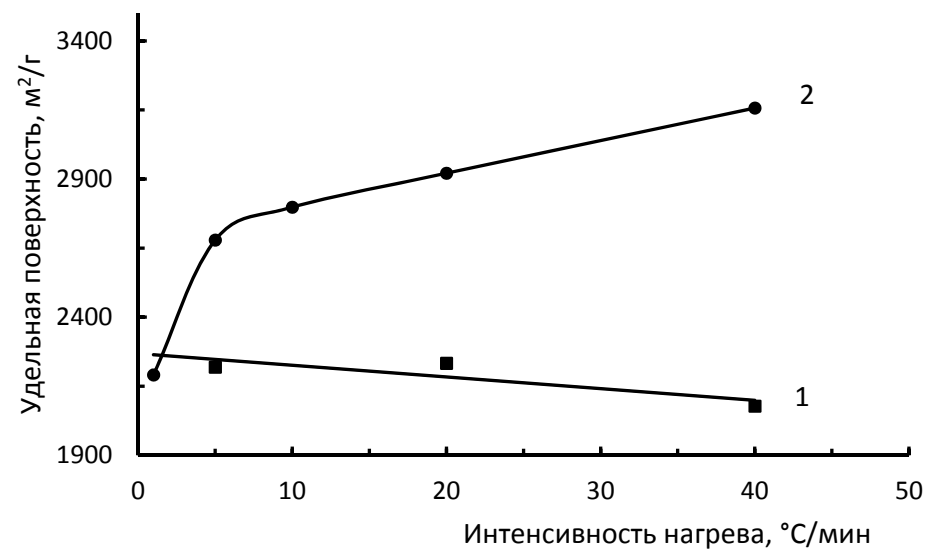

Рис. 3. Влияние скорости нагрева на удельную поверхность НУМ из щелочного лигнина (1) и этаноллигнина (2) пихты

Fig. 3. Effect of the heating rate on the surface area of NCMs from alkaline lignin (1) and ethanol lignin (2) of fir wood

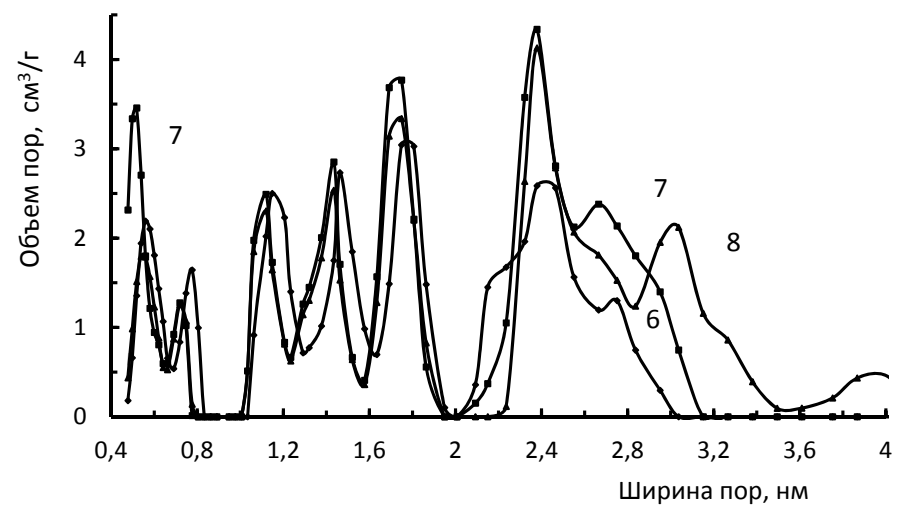

Рис. 4. Дифференциальные зависимости удельного объема пор от ширины пор, рассчитанные методом NLDFT для образцов НУМ № 6, 7 и 8, полученных из щелочного лигнина при скорости нагрева 5, 20 и $40{ }^{\circ} \mathrm{C}$ соответственно

Fig. 4. Differential dependencies specific pore volume on the width of the pores, calculated by NLDFT method for the samples of NCMs № 6, 7 and 8, obtained from alkaline lignin at the heating rate of 5, 20 and $40{ }^{\circ} \mathrm{C}$, respectively

полимодальный характер и демонстрируют три выраженные области микропор: ультрамикропор (0,48-0,68 нм), микропор (0,68-083 нм) и супермикропор (1,02-2,0 нм).

Наиболее существенные различия по распределению микропор для НУМ из щелочного и этанольного лигнина обнаружены в области ультрамикропор. Они характеризуются пиками с максимумами при 0,52 нм для образцов НУМ № 7 и № 1, полученных из щелочного и этанольного лигнина при скорости нагрева 20 и $1{ }^{\circ} \mathrm{C} /$ мин соответственно. Повышение скорости нагрева от 1 до $40{ }^{\circ} \mathrm{C} /$ мин при карбонизации лигнинов приводит к смещению максимумов пиков в сторону увеличения ширины пор до 0,56 нм с одновременным снижением высоты соответствующего пика. 


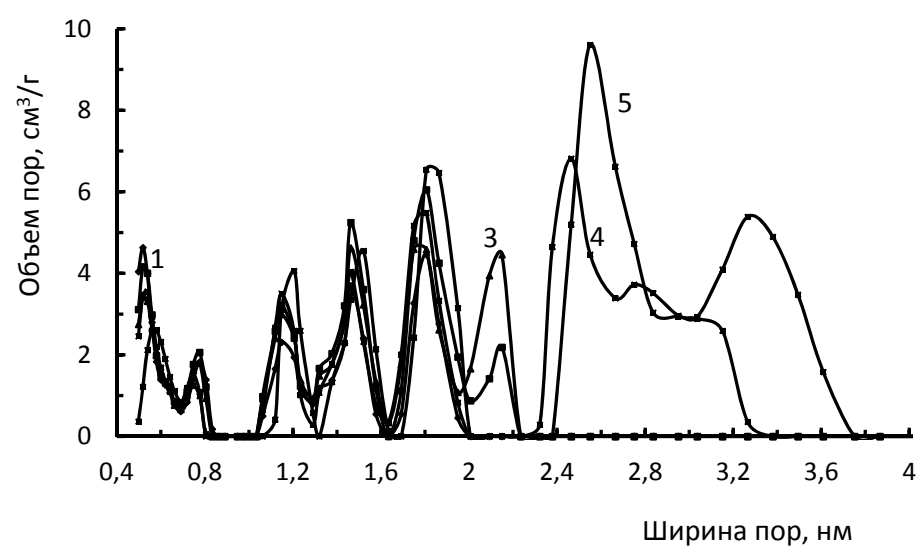

Рис. 5. Дифференциальные зависимости удельного объема пор от ширины пор, рассчитанные методом NLDFT для образцов НУМ № 1, 2, 3, 4 и 5, полученных из этаноллигнина при скорости нагрева 1, 5, 10, 20 и $40{ }^{\circ} \mathrm{C}$ соответственно

Fig. 5. Differential dependencies of specific volume of pores on the pore width, calculated by the NLDFT method for the samples of NCMs № 1, 2, 3, 4 and 5 obtained from ethanol lignin at the heating rate of 1, 5, 10, 20 and $40{ }^{\circ} \mathrm{C}$, respectively

Область микропор, как и область ультрамикропор характеризуется одним пиком с максимумом 0,78 нм. Тогда как в области супермикропор для обоих видов НУМ имеется каскад пор с тремя максимумами при 1,18, 1,52 и 1,8 нм. Заметного различия во вкладе этих пор в развитие удельной поверхности НУМ, полученных как из щелочного, так и этанольного лигнина пихты, не наблюдается.

В отличие от области микропор область, относящаяся к тонким мезопорам (от 2,0 до 4,0 нм), характеризуется наибольшими различиями. Для НУМ, полученных из щелочного лигнина, повышение скорости нагрева при карбонизации приводит к формированию широкого распределения пор по размерам с максимумом при 2,5 нм. В случае НУМ, полученных из этаноллигнина, увеличение скорости нагрева сопровождается формированием мезопор с тремя выраженными максимумами, соответствующими ширине 2,15, 2,51 и 3,31 нм. При увеличении скорости нагрева наблюдается смещение максимумов образующихся мезопор в сторону увеличения их размера. Для образцов №2 и 3 формирование мезопор ограничивается областью 2,0-2,15 нм, а для образцов №4 и 5 характерно формирование мезопор шириной 2,3-3,6 нм. При этом повышение скорости нагрева до $40{ }^{\circ} \mathrm{C} /$ мин сопровождается ростом объема пор шириной 2,51 нм и образованием пор шириной 3,31 нм.

На рис. 6 приведены электронно-микроскопические снимки углеродных материалов, полученных при различающихся скоростях нагрева этаноллигнина. Из сравнения снимков можно заключить, что при медленном нагреве формируется пористая структура карбонизованного продукта с порами большого размера (рис. 6 ). Повышение скорости нагрева до 40\% мин способствует увеличению пористости карбонизованного материала, обладающего порами меньшего диаметра (рис. 6б). Вероятно, это связано с тем, что при высоких скоростях нагрева интенсивно выделяющиеся летучие продукты создают в порах частиц избыточное давление, что приводит к формированию пористой структуры материала с ажурной морфологией.

$$
-397-
$$




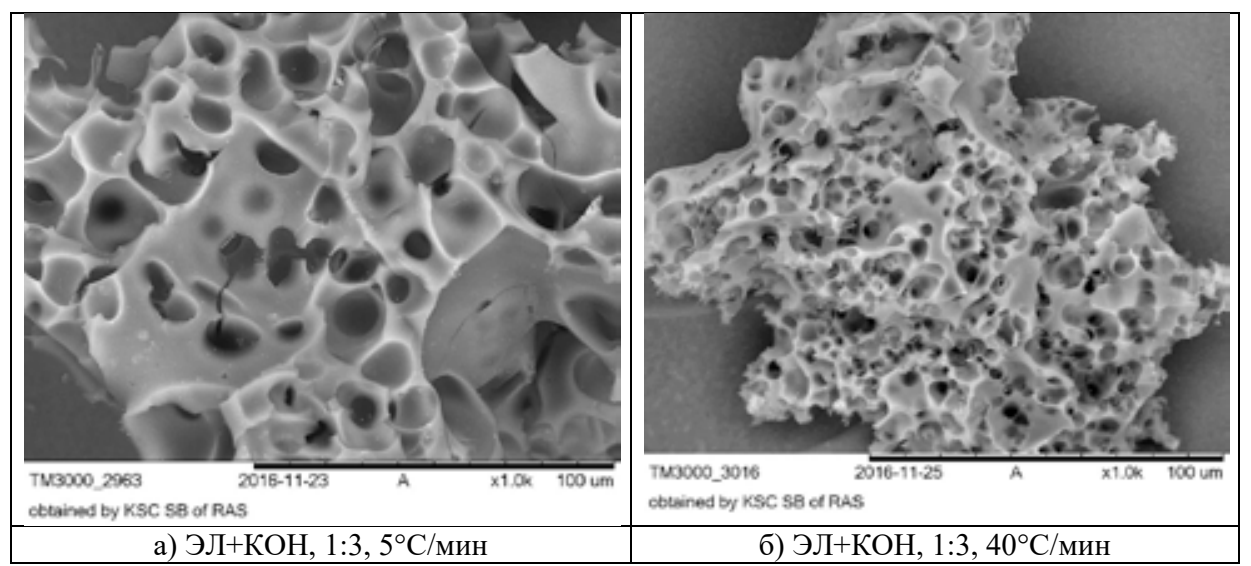

Рис. 6. Электронно-микроскопические снимки образцов НУМ, полученных карбонизацией этаноллигнина пихты в присутствии КОН при скорости нагрева до $800{ }^{\circ} \mathrm{C}: 5^{\circ} \mathrm{C} /$ мин (а) и $40{ }^{\circ} \mathrm{C} /$ мин (б)

Fig. 6. Electron microscopy images of samples of NCMs, obtained by carbonization of ethanol lignin fir wood in the presence of $\mathrm{KOH}$ at the rate of heating to $800{ }^{\circ} \mathrm{C}: 5{ }^{\circ} \mathrm{C} / \mathrm{min}$ (a) and $40{ }^{\circ} \mathrm{C} / \mathrm{min}$ (б)

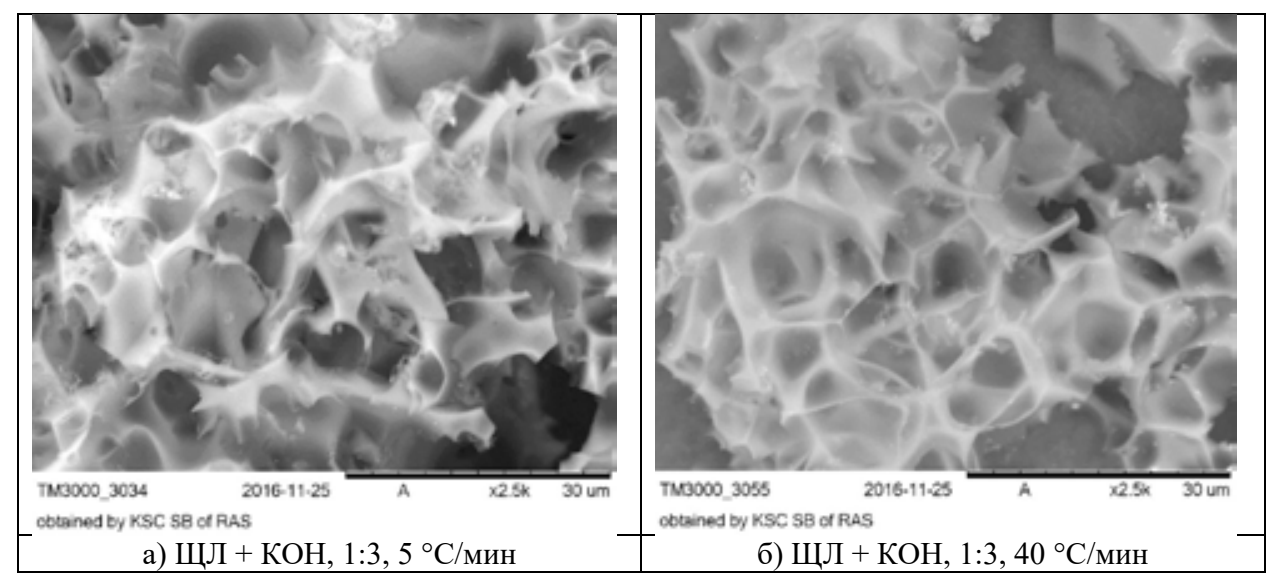

Рис. 7. Электронно-микроскопические снимки образцов НУМ, полученных карбонизацией щелочного лигнина пихты в присутствии КОН при скорости нагрева до $800{ }^{\circ} \mathrm{C}: 5{ }^{\circ} \mathrm{C} /$ мин (а) и $40{ }^{\circ} \mathrm{C} / \mathrm{мин} \mathrm{(б)}$

Fig. 7. Electron microscopy images of samples of NCMs, obtained by carbonation of alkaline lignin of fir wood in the presence of $\mathrm{KOH}$ at the rate of heating to $800{ }^{\circ} \mathrm{C}: 5{ }^{\circ} \mathrm{C} / \mathrm{min}$ (a) and $40{ }^{\circ} \mathrm{C} / \mathrm{min}$ (б)

Характер пористой структуры НУМ, полученных из щелочного лигнина пихты, в меньшей степени зависит от вариации скорости нагрева в процессе карбонизации по сравнению с НУМ из этаноллигнина (рис. 7).

Данные, полученные при изучении строения нанопористых углеродных материалов, свидетельствуют о том, что способ выделения лигнинов из древесины пихты оказывает значительное влияние на формирование пористой структуры и сорбционные свойства НУМ, полученных карбонизацией лигнина в присутствии гидроксида калия.

Образцы НУМ, полученные из лигнинов пихты, проявляют высокую сорбционную активность. Их сорбционная активность по бензолу при $25^{\circ} \mathrm{C}$ (от 0,88 до 1,41 г/г), превышает актив- 
ность зарубежных промышленных углеродных сорбентов в 2,5-4,0 раза, а для отечественных активных углей марки СКТ-3 и СКТ-10 - в 3,7-5,9 раза.

\section{Заключение}

Изучено влияние способа выделения лигнинов из древесины пихты на формирование пористой структуры и сорбционные свойства пористых углеродных материалов, полученных при вариации условий карбонизации лигнинов при $800{ }^{\circ} \mathrm{C}$ в присутствии гидроксида калия.

Показана возможность получения из лигнинов пихты нанопористых углеродных материалов с удельной поверхностью до $3157 \mathrm{~m}^{2} / \Gamma$ и объемом пор до $1,92 \mathrm{~cm}^{3} /$ г. Установлено, что полученные НУМ характеризуются высокой долей микропор (до 92 отн. \%) и средней шириной пор $1,88-2,43$ нм.

Установлено, что полученные НУМ обладают высокой сорбционной емкостью по бензолу (до 1,41 г/г) и превосходят зарубежные промышленные углеродные сорбенты по сорбционной емкости бензола в 2,5-4,0 раза, а отечественные активные угли марки СКТ-3 и СКТ-10 - в 3,7-5,9 раза.

Исследования выполнены за счет гранта Российского научного фонда (проект 16-1310326).

\section{Список литературы}

1. Lozano-Castello D., Alcaniz-Monge J., Cazorla-Amoros D., Linares-Solano A., Zhu W., Kapteijn F., Moulijn J.A. Adsorption properties of carbon molecular sieves prepared from an activated carbon by pitch pyrolysis. Carbon. 2005. V. 43. P. 1643-1651.

2. Bello G., Garcia R., Arriagada R., Sepulveda-Escribano A., Rodriguez-Reinoso F. Carbon molecular sieves from Eucalyptus globulus charcoal. Microporous and Mesoporous Materials. 2002. V.56. P.139.

3. Babel K., Janasiak D., Jurewicz K. Electrochemical hydrogen storage in activated carbons with different pore structures derived from certain lignocelluloses materials. Carbon. 2012. V. 50. P. 50175026.

4. Fatehi A.I., Loughlin K.F., Hassan M.M. A.I. Separation of methane-nitrogen mixtures by pressure swing adsorption using carbon molecular sieve. Gas Separation Purif. 1995. V. 9. P. 199-204.

5. Lillo-Ro' denas M.A., Marco-Lozar J.P., Cazorla-Amoro's D., Linares-Solano A. Activated carbons prepared by pyrolysis of mixtures of carbon precursor/alkaline hydroxide. J Anal Appl. Pyrolysis. 2007. Vol. 80. P. 166-174.

6. Чесноков Н.В., Микова Н.М., Иванов И.П., Кузнецов Б.Н. Журнал сибирского федерального университета. Химия. 2014. Т. 1. С. 42. [Chesnokov N.V., Mikova N.M., Ivanov I.P., Kuznetsov B.N. Journal of the Siberian Federal University. Chemistry. 2014. T. 1. P. 42. (In Russ.)]

7. Кузнецов Б.Н., Чесноков Н.В., Микова Н.М., Наймушина Л.В., Павленко Н.И., Селютин Г.Е. Химия в интересах устойчивого развития. 2002. Т. 10. С. 421. [Kuznetsov B.N., Chesnokov N.V., Mikova N.M., Naimushina L.V., Pavlenko N.I., Selyutin G.E. Chemistry for Sustainable Development. 2002. T. 10. P. 421. (In Russ.)]

$$
-399-
$$


8. Girgis B.S., El-Hendawy A.N.A. Porosity development in activated carbons obtained from date pits under chemical activation with phosphoric acid. Microporous and Mesoporous Materials. 2002. V. 52. P. 105-117.

9. Tay T., Ucar S., Karagoz S. Preparation and characterization of activated carbon from waste biomass. J. Hazard Mater. 2009. V. 165. P. 481-485.

10. Kijima M., Hirukawa T., Hanawa F., Hata T. Thermal conversion of alkaline lignin and its structured derivatives to porous carbonized materials. Biores. Technol. 2011. Vol. 102(10). P. 62796285 .

11. Babel K., Jurewicz K. Carbon. 2008. V. 46. P.1948.

12. http://www.micromeritics.com/

13. Scherdel C., Reichenauer G., Wiener M. Relationship between pore volumes and surface areas derived from the evaluation of $\mathrm{N}_{2}$-sorption data by DR-, BET- and t-plot. Microporous and Mesoporous Materials. 2010. V. 132(3). P. 572-575.

14. Lozano-Castello D., Suarez-Garsia F., Cazorla-Amoroz D., Linares-Solano A. Porous texture of carbons, in Carbons for Electrochemical Energy Storage Systems. CRC Press - Taylor and Francis Group, Boca Raton-New York. 2002, P. 115-162.

15. ISO 9277:2010-09 (E). Determination of the specific surface area of solids by gas adsorptionBET method.

16. Harkins W.D., Jura G.A. A vapor adsorption method for the determination of the area of a solid without the assumption of a molecular area and the areas occupied by nitrogen and other molecules on the surface of a solid. Journal of the American Chemical Society, 1944. V. 66. P. 1366-1373.

17. Webb P., Orr C. Analytical methods in the fine particle technology. Norcross GA.: Micromeritics Instrument Corporation, 1997. $301 \mathrm{p}$.

18. Lastoskie C., Gubbins K.E., Quirke N. Pore size distribution analysis of microporous carbons: a density functional theory approach. Journal of Physical Chemistry, 1993. V. 97. P. 4786-4796.

19. Landers J., Gor G. Yu., Neimark A.V. Density functional theory methods for characterization of porous materials. Colloids and Surfaces A: Physicochemical and Engineering Aspects, 2013. V. 437. P. 3-32.

20. Sing K.S.W., Everett D.H., Haul R.A.W. et al. Pure Appl. Chem. 1985. V. 57(4). P. 603-612.

21. Arriagada R., Bello G., Garcia R., Rodriguez-Reinoso F., Sepulveda-Escribano A. Carbon molecular sieves from hardwood carbon pellets. The influence of carbonization temperature in gas separation properties. Microporous Mesoporous Mater. 2005. V. 81. P. 161-167. 